\title{
Dobutamine Stress Echocardiography for Predicting the Postoperative Recovery of Left Ventricular Function in Patients with Chronic Severe Aortic Regurgitation: A Comparative Prospective Study
}

AMR ABO EL-FOTOH, M.D ; MOHAMED EL-FIKY, M.D. and MOHEY AL-ABBADY, M.D.

The Department of Cardiology, Nasser Health Institute, Egypt

\begin{abstract}
Background: Patients with chronic severe aortic regurgitation often present to our practice at a late stage. Patients with poor left ventricular function may or may not improve functionally or by left ventricular dimensions after surgery.
\end{abstract}

Aim of Study: We aim to answer this question; can dobutamine stress echocardiography predict the postoperative recovery of left ventricular function in patients with chronic severe aortic regurgitation?

Patients and Methods: This is a comparative prospective study from December 2014 to December 2015 in which we studied 49 patients undergoing aortic valve replacement for chronic severe aortic regurgitation. Patients were divided into 2 groups according to their resting ejection fraction, Group I with ejection fraction $<50 \%$ and Group II with ejection fraction $>50 \%$. Group I was further divided into Ia and Ib. Group IA included 16 patients who respond to dobutamine infusion by increase in ejection fraction $>30 \%$. Group IB included 16 patients who respond to dobutamine by increase in ejection fraction $<30 \%$. All the relevant clinical data was collected from all patients pre-operatively and 3 month followup visit. All patients in were stressed by infusion of dobutamine $20 \mathrm{ugm} / \mathrm{kg} / \mathrm{min}$ and the change in their End Systolic Volume (ESV) and End Diastolic Volume (EDV) and Ejection Fraction (EF) were evaluated.

Results: There was no hospital or 3 months mortality for the whole group. For Group II, the comparison between the response to aortic valve replacement and peak dobutamine reveals: The mean 3 months post-operative EF $56.87 \pm 6.03 \%$. The peak dobutamine EF was $68.3 \pm 7.5 \%$. There was statistically significant difference between the 2 values ( $p$-value $<0.001)$ i.e there relation was not obvious in this group.

For Group IA; the mean 3 months post-operative EF was $44.27 \pm 8.78 \%$. The peak dobutamine EF was $47.2 \pm 10.69 \%$. There was no statistically significant difference between the 2 values ( $p$-value $=0.177)$. For Group IB; the mean 3 months post-operative EF was $37.75 \pm 13.7 \%$. The peak dobutamine EF was $41.33 \pm 7.44 \%$. There was no statistically significant difference between the 2 values ( $p$-value $=0.175$ ).

Correspondence to: Dr. Amr Abo El-Fotoh, E-Mail: aaboalfotoh@yahoo.com
Conclusion: Dobutamine stress echocardiography was found to be predictor for post-operative left ventricular function in patients with chronic severe aortic regurgitation and impaired function.

Key Words: Dobutamine - Stress Echocardiography - Lt Ventricular Function - Aortic Regurgitation.

\section{Introduction}

THE ACC/AHA guidelines recommend surgical aortic valve replacement in for patients with symptomatic severe Aortic Regurgitation (AR) (class I), asymptomatic chronic severe aortic regurgitation with left ventricular systolic dysfunction (LVEF $<50 \%$ ) where the dysfunction is thought to be related to aortic regurgitation (class I), or those with moderate (ACC/AHA only) or severe aortic regurgitation undergoing cardiac surgery for other indications (class IIA and I respectively). Aortic valve replacement is also reasonable in severe aortic regurgitation with normal left ventricular systolic function but severe left ventricular dilatation (LV End Systolic Diameter [LVESD] $>50 \mathrm{~mm}$ or LV End Diastolic Diameter [LVEDD] $>70 \mathrm{~mm}$ [ESC only] (class IIA) and can be considered in severe aortic regurgitation with normal left ventricular ejection fraction but with progressive left ventricular dilatation (LVEDD >65mm; ACC/AHA only) (class IIB) [1,2].

Similar to patients with aortic stenosis, exercise testing can unmask symptomatic patients previously classified as being asymptomatic or with equivocal symptoms who would receive a significant mortality benefit from aortic valve replacement compared to delaying surgery. However, the progression of disease in asymptomatic severe chronic aortic regurgitation is much slower based on the natural history of the disease with an estimated annual 
progression (requiring aortic valve replacement or death) is approximately 6\% [3]. Monitoring for disease progression is particularly important to perform timely intervention prior to the development of irreversible dysfunction. In patients who do not meet the criteria for aortic valve replacement, exercise stress testing can also be used to assess contractile reserve to detect subclinical left ventricular dysfunction. Despite being asymptomatic or only mildly symptomatic, the absence of contractile reserve is more predictive of the development of systolic dysfunction both at follow-up (medical therapy) and post-operatively than parameters obtained at rest $[\mathbf{4 , 5}]$.

Irreversible changes in the left ventricular function can develop in some patients with aortic regurgitation even after successful aortic valve replacement. This subset of patients may have persistent cardiomegaly and depressed left ventricular function. So, in order to minimize the risk of postoperative left ventricular dysfunction, every effort should be made to operate on patients before serious left ventricular dysfunction occurs [7]. Since aortic regurgitation has complex effect on both preload and afterload, the selection of appropriate indices of ventricular contractility is a challenge. Simple left ventricular end diastolic volume and ejection phase indices such as ejection fraction and ventricular fractional shortening are too strongly influenced by loading to be accurate indication of ventricular contractility but may be useful empirical predictors of post-operative function [8].

Pre-operative left ventricular end systolic volume and dimension are largely preload independent and are good predictors of post-operative left ventricular function [8]. The relationship between end systolic wall stress and ejection fraction or percent fractional shortening may be even more useful [9]. Failure of the normal increase in ejection fraction or the decline of end systolic volume during exercise, as determined by radionuclide angiography is considered as a marker of depressed myocardial function and an indication for surgery [10].Dobutamine stress echocardiography is a simple, safe, rapid, relatively low cost and non-invasive cardiac stress test. Recently, its application is extended beyond coronary artery disease to valvular heart disease. Application in mitral and aortic valve diseases is useful in assessment of severity and understanding of hemodynamics of these lesions [11].In chronic severe aortic regurgitation the inotropic effect of dobutamine can be used to identify subsets of patients in whom the systolic performance is within normal limits but intrinsic myocardial contractility is depressed.

\section{Patients and Methods}

Forty-nine consecutive patients with chronic severe aortic regurgitation in need for aortic valve replacement were included in the study.

Place: Nasser Health Institute, from December 2014 to December 2015.

Exclusions were: Patients with recent onset of regurgitation (six months or less), valvular stenosis (aortic valve area $<1 \mathrm{~cm}$ ), regional left ventricular dysfunction consistent with prior myocardial infarction, unstable coronary syndromes in the previous six months, hypertrophic cardiomyopathy, antiarrhythmic therapy for ventricular tachyarrhythmia, and known hypersensitivity to dobutamine.

- All patients were subjected to the following:

A- Full history taken especially history regarding dyspnea, palpitations and chest pain.

B- Full general and local cardiac examination.

C- Height and weight were measured to calculate the body surface area using the formula:

$$
\mathrm{BSA}=0.007184 \mathrm{X} \mathrm{W} 0.425 \times \mathrm{H} 0.725 \text { [7] }
$$

D- Resting 12 leads electrocardiography (ECG) for diagnosis of arrhythmia, conduction disturbances and criteria of left ventricular hypertrophy.

E- X-ray chest for diagnosis of cardiothoracic ratio and pulmonary congestion.

F- Diagnostic coronary angiography for patients more than 40 years to exclude coronary ischemia.

G- Echo-Doppler examination (resting measurements).

All patients were studied using parasternal long axis and short axis views, apical two and four chamber views, the following parameters were noted;

- Left ventricular end diastolic dimensions and end systolic dimensions were determined from the $\mathrm{M}$-mode tracings according to the recommendations of the American Society of Echocardiography [13].

End diastole is defined as the onset of the QRS and end systole is determined by the most posterior position of the septum.

- Septal and posterior wall thickness were measured at the onset of the ORS complex of the ECG by leading edge methodology (from the leading edge 
to the leading edge) and by using the thinnest continuous echo lines.

- Left ventricular fractional shortening was calculated by the computer system of the echocardiography machine by using the formula:

$$
\mathrm{FS}=\frac{\mathrm{EDD}-\mathrm{ESD}}{\mathrm{EDD}}
$$

- Left ventricular ejection fraction was measured by using the (Teich-method) and psimson's methods.

- Calculation of the left ventricular volumes and ejection fraction: Left ventricular volumes were calculated using modified Simpson"s method which divides the left ventricle into 20 slices with left ventricular long axis at 2 chambers or 4 chamber view using the formula:

Volume $=\begin{array}{ll}\text { II } \mathbf{L} & \begin{array}{l}20 \\ \mathbf{4}\end{array} \overline{20}\end{array} \quad \mathrm{i}=1$

Where;

- asi is the disc diameter at the apical 2 chamber.

- bsi is the disc diameter at the apical 4 chamber.

- $\mathrm{L}$ is the maximum length from 2 chamber or 4 chamber [14].

Endocardial borders were traced in both systole and diastole in both apical views. The papillary muscles were excluded from the cavity size. The frame captured at the R wave of the ECG was considered to be the end diastolic frame, and the frame with smaller left ventricular cavity was considered as the end systolic frame.

Ejection fraction was calculated from the difference between the end diastolic and end systolic volumes by the equation:

$$
\mathrm{EF}=\frac{\mathrm{EDV}-\mathrm{ESV}}{\mathrm{EDV}}
$$

The ejection fraction was also calculated by the single plane method by tracking the end systolic volume and end diastolic volume in the apical 4 chamber view.

End systolic volume and end diastolic volume were correlated to body surface area to calculate end systolic volume and end diastolic volume index.

- Measuring the extent of distribution of diastolic flow within the left ventricle by using pulsed Doppler; $(1+)$ mild if the jet could be traced up to $1 \mathrm{~cm}$ into the left ventricle, $(2+)$ moderate when the jet traveled to the level of the base of the mitral leaflet, $(3+)$ moderately severe if the jet extend to the mitral leaflet tips, (4+) severe if the jet extended beyond the leaflet tips [15]

- Measurement of aortic valve area: Aortic valve area was measured in patients with combined aortic stenosis and aortic regurgitation by applying the continuity equation. Because blood flow or stroke volume is equal to velocity times cross sectional area and blood flow through the Left Ventricular Outflow Tract (LVOT) must equal flow through the valve (AS), then LVOT (area) $X$ LVOT (velocity) = AS (area) X AS (velocity) or aortic valve area $=$ LVOT (area) X LVOT (velocity)/AS (velocity) [11,12]. We exclude patients with aortic valve area $<1 \mathrm{~cm}^{2}$ [15].

\section{Dobutamine stress echocardiography:}

The examination was performed with the patient lying in a left lateral position with continuous ECG monitoring and recorded for later analysis. After recording the resting measurements, dobutamine infusion was started at a dose of $5 \mathrm{ug} / \mathrm{kg} / \mathrm{min}$. and increased gradually every 3 minutes to $10 \mathrm{ug} / \mathrm{kg} / \mathrm{min}$ then to $15 \mathrm{ug} / \mathrm{kg} / \mathrm{min}$ then to $20 \mathrm{ggm} / \mathrm{kg} /$ minute. In order to determine the ideal dobutamine dose that augments the ejection fraction maximally without causing undesired side effects we perform full test dobutamine (40ug/kg/min) to 15 patients. Echocardiographic images were obtained and the previous (baseline) measurements were all repeated at the end of every stage. Heart rate and blood pressure were recorded at the end of each stage. End points of our test are to reach to the maximum dose or occurrence of side effects.

The echocardiographic images and measurements were recorded on videotapes and re-analyzed by the same observer or another observer.

Follow-up data were collected after 3 months of surgery including; full history especially improvement of NYHA functional class, full general and cardiac examination, echocardiographic assessment including all the resting data recorded before surgery.

To detect interobserver and interabserver variability:

\section{A- Interobserver variability:}

- At rest: 15 patients were studied by another experienced echocardiographer on the same day of the first study and left ventricular ejection fraction was calculated by modified biplane Simpson's method and Teich-method. 
- During exercise: 15 patients were studied on video tapes by another experienced echo cardiographer and left ventricular ejection fraction was calculated by modified biplane Simpson's method.

\section{B- Intraobserver variability:}

- At rest: The same echocardiographer repeated the examination and measurements in 15 patients during another setting in the same day.

- With exercise: The same echocardiographer repeated the measurements in 15 patients on videotapes.

\section{Results}

Patients were divided into 2 groups according to their resting ejection fraction, Group I with ejection fraction $<50 \%$ and Group II with ejection fraction $>50 \%$. Group I was further subdivided into Group IA and Group IB. Group IA included 16 patients who responded to dobutamine infusion by increase in ejection fraction $>30 \%$. Group IB included 16 patients who responded to dobutamine infusion by increase in ejection fraction $<30 \%$.

\section{Group II:}

Included 17 patients with a mean age $25.9 \pm 10.5$ years. Group II included 12 males (70.6\%) and 5 females (29.4\%). Group II included 12 patients in NYHA functional class II (70.6\%) and 5 patients in NYHA functional class III (29.4\%).

\section{Response of Group II patients to aortic valve replacement:}

Resting EF ranged from 54.6 to 71.9 with a mean $62.3 \pm 6$. The 3 months post-operative mean EF decreased from $62.3 \pm 6$ to $56.8 \pm 6$ which is statistically non-significant reduction $(p>0.05)$.

Response of Group II patients to peak dobutamine:

With peak dobutamine resting mean EF value increased from $62.3 \pm 6$ to $68.3 \pm 7.5$ which is statistically non-significant increase $(p<0.003)$ (Table 1).

Comparison between the response to aortic valve replacement and peak dobutamine:

The mean 3 months post-operative EF was $56.78 \pm 6.03$. The peak dobutamine EF was $68 . \pm 7.5$. There was statistically significant difference between the values ( $p$-value <0.001). By application of Mc Nemar test of agreement to detect the agreement between improvement with dobutamine and improvement after surgery there was statistically significant difference between the effects of both of them on the ejection fraction i.e dobutamine is not a predictor of post-operative ejection fraction in this group (Table 2).

Improvement in dyspnea functional class in Group II:

In the first 3 months post-operatively $47 \%$ of patients were in NYHA functional class II and $53 \%$ were in NYHA functional class I. The improvement in dyspnea functional class in group II was considered statistically significant $(p<0.001)$.

Group I: Group included 32 patients which is further subdivided to:

- Group IA: Group IA included 16 patients with a mean age $28.4 \pm 11.3$ years, 12 patients were males $(75 \%)$ and 4 patients were females (25\%). Group IA included 3 hypertensive patients (18.8\%) and 1 diabetic patient $(6.3 \%)$. Group IA included 4 patients in NYHA functional class II and 12 patients in NYHA functional class III. Group IA included 3 ex-smokers (18.75\%), 1 smoker $(6.25 \%)$ and 12 non-smokers $(75 \%)$.

Response of Group IA patients to aortic valve replacement:

EF ranged from 17.6 to 48.3 with a mean value $29.3 \pm 11.1 \%$. The 3 months post-operative mean EF value increased from $29.3 \pm 11.1$ to 44.3 which is statistically significant increase $(p<0.001)$ (Table 3).

Response of Group IA patients to peak dobutamine:

With peak dobutamine resting mean EF value increased from $29.3 \pm 11.1$ to $47.2 \pm 10.7$ which is statistically significant increase $(p<0.001)$ (Table 4).

Comparison between the response to aortic valve replacement and peak dobutamine:

The mean 3 months postoperative EF was 44.27 $\pm 8.78 \%$. The peak dobutamine EF was $47.20 \pm$ $10.69 \%$. There was no statistically significant difference between the two values ( $p$-value $=$ 0.177) (Table 5).

- Group IB: Group IB included 16 patients with mean age $35.4 \pm 8.4$ years, 2 females $(12.5 \%)$ and 14 males $(87.5 \%)$. Group IB included 4 patients with hypertension (25\%) and no diabetic patients. Group IB included 2 ex-smokers (12.5\%), 1 smoker $(6.25 \%)$ and 13 non-smokers (81.25\%). Group IB included 6 patients in NYHA functional class II $(12.5 \%)$ and 10 patients in NYHA functional class III $(87.5 \%)$. 


\section{Response of Group IB patients to aortic valve replacement:}

Resting EF ranged from 26.7 to 47.2 with a mean value $34.9 \pm 7 \%$. The 3 months post-operative mean $\mathrm{EF}$ value increased from $34.9 \pm 7$ to 37.7 $\pm 13.7 \%$ which is statistically non-significant increase $(p=0.319)$ (Table 6).

Response of Group IB patients to peak dobutamine:

With peak dobutamine resting mean EF value increased from $34.9 \pm 7.1$ to $41.3 \pm 7.4 \%$ which is statistically non-significant increase $(p<0.44)$ (Table 7).

Comparison between the response of Group IB patients to aortic valve replacement and dobutamine infusion:

The mean 3 months post-operative EF was $37.75 \pm 13.70 \%$. The peak dobutamine EF was 41.33 $\pm 7.44 \%$. There was no statistically significant difference between the two values $(p$-value $=0.175)$ (Table 8).

Comparison between the response of the two Groups (IA and IB) to aortic valve replacement:

$\mathrm{EF}$ in Group IA the percentage change in the mean value was $62.5 \pm 42.8$ and in Group IB it increased by $7.8 \pm 31 \%$. The increase in EF in Group IA was considered statistically significant than the in Group IB $(p<0.001)$ (Table 9).

Comparison between the responses of the 2 groups to dobutamine infusion:

EF in Group IA the percentage change in the mean value was $62 \pm 43 \%$ and in Group IB it increased by $8 \pm 31 \%$. The increase in EF in Group IA was considered statistically significant than the increase in Group IB $(p<0.001)$ (Table 10).

\section{The target dose of dobutamine:}

The test was performed in 15 patients by dobutamine infusion up to $40 \mathrm{u}$ to see whether the improvement in echocardiographic variables with $40 \mathrm{u}$ is more than with $20 \mathrm{u}$ and there was no statistical difference between the $20 \mathrm{u}$ and $40 \mathrm{u}$ values of end systolic volume, end systolic volume index, end diastolic volume, end diastolic volume index, stroke volume and ejection fraction (Table 11).

\section{Improvement of NYHA class:}

As regards the pre-operative functional class in Group IA there were 4 patients (25\%) in NYHA class II and 12 patients (75\%) in class III.

The pre-operative functional class in Group IB there were 2 patients $(12.5 \%)$ in NYHA class II and 14 patients $(87.5 \%)$ in NYHA class III. In the first three months post-operatively in Group IA 15 patients $(93.75 \%)$ were in class II and 1 patient $(6.25 \%)$ was in class III. Improvement by I grade occurs in $40 \%$ and improvement by more than I grade occurs in $60 \%$ of the patients. The improvement of dyspnea functional class in Group IA patients was statistically significant ( $p$-value $<0.001)$. In the first 3 months post-operatively in Group IB 6 patients $(37.5 \%)$ were in NYHA class II and 10 patients $(62.5 \%)$ were in NYHA class III. No change in NYHA functional class occurs in $60 \%$ and $40 \%$ of the patients improved 1 grade. The improvement in dyspnea functional class in Group IB patients was statistically non-significant $(p$-value $=0.22)$.

Table (1): Resting and post-operative echocardiographic variables in Group II.

\begin{tabular}{lccc}
\hline $\begin{array}{l}\text { Echocardiographic } \\
\text { variable }\end{array}$ & $\begin{array}{c}\text { Resting } \\
\text { (mean value) }\end{array}$ & $\begin{array}{c}\text { Post-operative } \\
\text { (mean value) }\end{array}$ & $\begin{array}{c}\text { Sig. } \\
\text { (2 tailed) }\end{array}$ \\
\hline ESV & $95 \pm 33$ & $58 \pm 25$ & 0.001 \\
ESVI & $55 \pm 21$ & $33 \pm 15$ & 0.001 \\
EDV & $251 \pm 60$ & $132 \pm 43$ & 0.001 \\
EDVI & $145 \pm 40$ & $76 \pm 26$ & 0.001 \\
EF & $62 \pm 6$ & $57 \pm 6$ & 0.05 \\
SV & $155 \pm 33$ & $74 \pm 22$ & 0.001 \\
\hline
\end{tabular}

ESV: End Systolic Volume. ESVI : End Systolic Volume Index. EDV: End Diastolic Volume. EDVI: End Diastolic Volume Index. EF : Ejection fraction. $\quad$ SV : Stroke Volume.

Table (2): Response of echocardiographic variables to dobutamine in Group II.

\begin{tabular}{lccc}
\hline $\begin{array}{l}\text { Echocardiographic } \\
\text { variable }\end{array}$ & Resting & $\begin{array}{c}\text { Peak } \\
\text { dobutamine }\end{array}$ & $\begin{array}{c}p- \\
\text { value }\end{array}$ \\
\hline ESV & $95 \pm 33$ & $86 \pm 40$ & 0.162 \\
ESVI & $55 \pm 21$ & $50 \pm 24$ & 0.144 \\
EDV & $251 \pm 60$ & $266 \pm 59$ & 0.098 \\
EDVI & $145 \pm 40$ & $153 \pm 38$ & 0.123 \\
EF & $62 \pm 6$ & $68 \pm 7$ & 0.003 \\
SV & $155 \pm 33$ & $181 \pm 31$ & 0.002 \\
\hline
\end{tabular}

ESV: End Systolic Volume. ESVI : End Systolic Volume Index. EDV: End Diastolic Volume. EDVI: End Diastolic Volume Index. EF : Ejection fraction. SV : Stroke Volume.

Table (3): Comparison between peak dobutamine and postoperative echocardiographic variables in Group II.

\begin{tabular}{lccc}
\hline $\begin{array}{l}\text { Echocardiographic } \\
\text { variable }\end{array}$ & $\begin{array}{c}\text { Post- } \\
\text { operative }\end{array}$ & $\begin{array}{c}\text { Peak } \\
\text { dobutamine }\end{array}$ & $\begin{array}{c}p \text { - } \\
\text { value }\end{array}$ \\
\hline ESV & $58 \pm 25$ & $86 \pm 40$ & 0.001 \\
ESVI & $33 \pm 15$ & $50 \pm 24$ & 0.002 \\
EDV & $132 \pm 43$ & $266 \pm 59$ & 0.001 \\
EDVI & $76 \pm 26$ & $153 \pm 38$ & 0.001 \\
EF & $57 \pm 6$ & $68 \pm 7$ & 0.001 \\
SV & $74 \pm 22$ & $181 \pm 31$ & 0.001 \\
\hline
\end{tabular}

ESV: End Systolic Volume. ESVI : End Systolic Volume Index. EDV: End Diastolic Volume. EDVI: End Diastolic Volume Index EF : Ejection fraction. SV : Stroke Volume. 
Table (4): Resting and post-operative echocardiographic variables in Group IA.
Table (7): Resting and post-operative echocardiographic variables in Group IB.

\begin{tabular}{|c|c|c|c|c|c|c|c|}
\hline $\begin{array}{l}\text { Echocardiographic } \\
\text { variable }\end{array}$ & Resting & $\begin{array}{c}\text { Peak } \\
\text { dobutamine }\end{array}$ & $\begin{array}{c}p- \\
\text { value }\end{array}$ & $\begin{array}{l}\text { Echocardiographic } \\
\text { variable }\end{array}$ & Resting & $\begin{array}{l}\text { Post- } \\
\text { operative }\end{array}$ & $\begin{array}{c}p- \\
\text { value }\end{array}$ \\
\hline ESV & $194 \pm 75$ & $104 \pm 46$ & 0.001 & ESV & $261 \pm 102$ & $191 \pm 91$ & 0.001 \\
\hline ESVI & $106 \pm 43$ & $56 \pm 23$ & 0.001 & ESVI & $141 \pm 56$ & $103 \pm 50$ & 0.001 \\
\hline EDV & $277 \pm 98$ & $182 \pm 92$ & 0.001 & EDV & $393 \pm 125$ & $280 \pm 102$ & 0.001 \\
\hline EDVI & $150 \pm 53$ & $103 \pm 44$ & 0.002 & EDVI & $212 \pm 68$ & $160 \pm 58$ & 0.001 \\
\hline $\mathrm{EF}$ & $29 \pm 11$ & $44 \pm 9$ & 0.001 & EF & $35 \pm 7$ & $38 \pm 14$ & 0.319 \\
\hline SV & $82 \pm 41$ & $84 \pm 51$ & 0.781 & SV & $136 \pm 35$ & $102 \pm 33$ & 0.033 \\
\hline
\end{tabular}

Table (5): Response of echocardiographic variables to dobutamine in Group IA.
Table (8): Response of echocardiographic to dobutamine in Group IB.

\begin{tabular}{|c|c|c|c|c|c|c|c|}
\hline $\begin{array}{l}\text { Echocardiographic } \\
\text { variable }\end{array}$ & Resting & $\begin{array}{c}\text { Peak } \\
\text { dobutamine }\end{array}$ & $\begin{array}{c}p- \\
\text { value }\end{array}$ & $\begin{array}{l}\text { Echocardiographic } \\
\text { variable }\end{array}$ & Resting & $\begin{array}{c}\text { Peak } \\
\text { dobutamine }\end{array}$ & $\begin{array}{c}p- \\
\text { value }\end{array}$ \\
\hline ESV & $194 \pm 75$ & $152 \pm 60$ & 0.001 & ESV & $261 \pm 102$ & $221 \pm 94$ & 0.001 \\
\hline ESVI & $106 \pm 43$ & $83 \pm 35$ & 0.001 & ESVI & $141 \pm 56$ & $120 \pm 52$ & 0.001 \\
\hline EDV & $277 \pm 98$ & $288 \pm 87$ & 0.139 & EDV & $393 \pm 125$ & $364 \pm 121$ & 0.016 \\
\hline EDVI & $150 \pm 53$ & $156 \pm 47$ & 0.143 & EDVI & $212 \pm 68$ & $196 \pm 67$ & 0.018 \\
\hline $\mathrm{EF}$ & $29 \pm 11$ & $47 \pm 11$ & 0.001 & $\mathrm{EF}$ & $35 \pm 7$ & $41 \pm 7$ & 0.05 \\
\hline SV & $82 \pm 41$ & $135 \pm 46$ & 0.001 & SV & $136 \pm 35$ & $143 \pm 33$ & 0.05 \\
\hline $\begin{array}{l}\text { ESV: End Systolic Vo } \\
\text { EDV: End Diastolic V } \\
\text { EF : Ejection fraction }\end{array}$ & $\begin{array}{l}\text { ESV } \\
\text { EDV } \\
\text { SV }\end{array}$ & $\begin{array}{l}\text { d Systolic Vo } \\
\text { d Diastolic V } \\
\text { coke Volume. }\end{array}$ & $\begin{array}{l}\text { dex. } \\
\text { dex. }\end{array}$ & $\begin{array}{l}\text { ESV: End Systolic Vo } \\
\text { EDV: End Diastolic V } \\
\text { EF : Ejection fraction }\end{array}$ & $\begin{array}{l}\text { EDVI } \\
\text { SV }\end{array}$ & $\begin{array}{l}\text { Systolic Vol } \\
\text { d Diastolic Vo } \\
\text { oke Volume. }\end{array}$ & $\begin{array}{l}\text { ndex. } \\
\text { Index. }\end{array}$ \\
\hline
\end{tabular}

Table (6): Comparison between peak dobutamine and postoperative echocardiographic variables in Group IA.

\begin{tabular}{|c|c|c|c|c|c|c|c|}
\hline $\begin{array}{l}\text { Echocardiographic } \\
\text { variable }\end{array}$ & $\begin{array}{c}\text { Post- } \\
\text { operative }\end{array}$ & $\begin{array}{c}\text { Peak } \\
\text { dobutamine }\end{array}$ & $\begin{array}{c}p- \\
\text { value }\end{array}$ & $\begin{array}{l}\text { Echocardiographic } \\
\text { variable }\end{array}$ & $\begin{array}{c}\text { Post- } \\
\text { operative }\end{array}$ & $\begin{array}{c}\text { Peak } \\
\text { dobutamine }\end{array}$ & $\begin{array}{c}p- \\
\text { value }\end{array}$ \\
\hline ESV & $104 \pm 46$ & $152 \pm 60$ & 0.001 & ESV & $191 \pm 91$ & $221 \pm 94$ & 0.001 \\
\hline ESVI & $56 \pm 23$ & $83 \pm 35$ & 0.001 & ESVI & $103 \pm 50$ & $120 \pm 52$ & 0.001 \\
\hline EDV & $182 \pm 92$ & $288 \pm 87$ & 0.001 & EDV & $280 \pm 102$ & $364 \pm 121$ & 0.001 \\
\hline EDVI & $103 \pm 44$ & $156 \pm 47$ & 0.001 & EDVI & $160 \pm 58$ & $196 \pm 67$ & 0.001 \\
\hline $\mathrm{EF}$ & $44 \pm 9$ & $47 \pm 11$ & 0.177 & $\mathrm{EF}$ & $38 \pm 14$ & $41 \pm 7$ & 0.175 \\
\hline SV & $84 \pm 51$ & $135 \pm 46$ & 0.001 & SV & $102 \pm 33$ & $143 \pm 33$ & 0.004 \\
\hline
\end{tabular}

ESV: End Systolic Volume. ESVI : End Systolic Volume Index. EDV: End Diastolic Volume. EDVI : End Diastolic Volume Index. EF : Ejection fraction. SV : Stroke Volume.
Table (9): Comparison between peak dobutamine and postoperative echocardiographic variables in Group IB.

ESV: End Systolic Volume. ESVI : End Systolic Volume Index. EDV: End Diastolic Volume. EDVI : End Diastolic Volume Index. $\mathrm{EF}:$ Ejection fraction. SV : Stroke Volume.

Table (10): Comparison between responses of Groups IA \& IB aortic valve replacement.

\begin{tabular}{llllllll}
\hline \multirow{2}{*}{$\begin{array}{l}\text { Echocardiographic } \\
\text { variable }\end{array}$} & \multicolumn{3}{c}{ Group IA } & \multicolumn{3}{c}{ Group IB } & $\begin{array}{c}p \text { - } \\
\text { value }\end{array}$ \\
\cline { 2 - 7 } & Resting & Post-op. & \% change & Resting & Post-op. & \% change \\
\hline ESV & $194 \pm 75$ & $103 \pm 46$ & $43 \pm 19$ & $261 \pm 102$ & $191 \pm 91$ & $29 \pm 17$ & 0.036 \\
ESVI & $106 \pm 43$ & $56 \pm 23$ & $43 \pm 19$ & $141 \pm 56$ & $103 \pm 49$ & $29 \pm 17$ & 0.036 \\
EDV & $277 \pm 98$ & $182 \pm 92$ & $27 \pm 25$ & $393 \pm 125$ & $280 \pm 102$ & $23 \pm 19$ & 0.588 \\
EDVI & $150 \pm 53$ & $103 \pm 44$ & $27 \pm 25$ & $212 \pm 68$ & $196 \pm 67$ & $23 \pm 19$ & 0.588 \\
SV & $82 \pm 41$ & $84 \pm 51$ & $9 \pm 34$ & $136 \pm 35$ & $102 \pm 33$ & $18 \pm 36$ & 0.038 \\
EF & $29 \pm 11$ & $44 \pm 9$ & $62 \pm 43$ & $35 \pm 7$ & $41 \pm 7$ & $8 \pm 31$ & 0.001 \\
\hline ESV : End Systolic Volume. & \multicolumn{5}{c}{ ESVI : End Systolic Volume Index. } \\
EDV : End Diastolic Volume. & \multicolumn{5}{c}{ EDVI : End Diastolic Volume Index. } \\
EF : Ejection fraction. & \multicolumn{5}{c}{ SV Stroke Volume. } \\
\end{tabular}


Table (11): Comparison between the response of Groups IA \& IB to peak dobutamine.

\begin{tabular}{|c|c|c|c|c|c|c|c|}
\hline \multirow[b]{2}{*}{$\begin{array}{l}\text { Echocardiographic } \\
\text { variable }\end{array}$} & \multicolumn{3}{|c|}{ Group IA } & \multicolumn{3}{|c|}{ Group IB } & \multirow{2}{*}{$\begin{array}{c}p- \\
\text { value }\end{array}$} \\
\hline & Resting & $\begin{array}{c}\text { Peak } \\
\text { dobutamir }\end{array}$ & $\begin{array}{c}\% \\
\text { change }\end{array}$ & Resting & $\begin{array}{c}\text { Peak } \\
\text { dobutamin }\end{array}$ & $\begin{array}{c}\% \\
\text { hange }\end{array}$ & \\
\hline ESV & $194 \pm 75$ & $152 \pm 60$ & $21 \pm 10$ & $261 \pm 102$ & $221 \pm 94$ & $16 \pm 8$ & 0.111 \\
\hline ESVI & $106 \pm 43$ & $83 \pm 35$ & $21 \pm 10$ & $141 \pm 56$ & $120 \pm 52$ & $16 \pm 8$ & 0.111 \\
\hline EDV & $277 \pm 98$ & $288 \pm 87$ & $-7 \pm 13$ & $393 \pm 124$ & $364 \pm 121$ & $7 \pm 11$ & 0.004 \\
\hline EDVI & $150 \pm 53$ & $156 \pm 47$ & $-7 \pm 13$ & $212 \pm 68$ & $196 \pm 67$ & $7 \pm 11$ & 0.004 \\
\hline SV & $82 \pm 41$ & $135 \pm 46$ & $85 \pm 58$ & $136 \pm 35$ & $143 \pm 33$ & $7 \pm 20$ & 0.001 \\
\hline $\mathrm{EF}$ & $29 \pm 11$ & $47 \pm 11$ & $71 \pm 37$ & $35 \pm 7$ & $41 \pm 7$ & $19 \pm 8$ & 0.001 \\
\hline
\end{tabular}

Table (12): Difference between echocardiographic variables with $20 \mathrm{u}$ and $40 \mathrm{u}$ dobutamine.

\begin{tabular}{llll}
\hline $\begin{array}{l}\text { Echocardiographic } \\
\text { variable }\end{array}$ & $20 \mathrm{u}$ & $40 \mathrm{u}$ & $\begin{array}{c}p \text { - } \\
\text { value }\end{array}$ \\
\hline ESV & $236 \pm 94$ & $229 \pm 90$ & 0.083 \\
EDV & $377 \pm 131$ & $372 \pm 148$ & 0.554 \\
SV & $141 \pm 41$ & $153 \pm 62$ & 0.198 \\
EF & $38 \pm 4$ & $40 \pm 2$ & 0.142 \\
\hline
\end{tabular}

ESV: End Systolic Volume. ESVI : End Systolic Volume Index. EDV: End Diastolic Volume. EDVI: End Diastolic Volume Index $\mathrm{EF}$ : Ejection fraction. $\quad \mathrm{SV}:$ Stroke Volume.

Table (13): Demographic data.

\begin{tabular}{llll}
\hline & Group IA & Group IB & Group II \\
\hline Number & 16 & 16 & 17 \\
Age (mean) & $28.4 \pm 11.3$ & $35 \pm 8.4$ & $25.9 \pm 10.5$ \\
Sex & $75 \%$ male, & $87.5 \%$ male, & $70.6 \%$ male, \\
& $25 \%$ female & $12.5 \%$ female & $29.4 \%$ female \\
\hline
\end{tabular}

\section{Discussion}

The optimal timing of valve surgery in patients with chronic severe aortic regurgitation remains difficult. The clinician must weigh the risks of surgery and the prosthetic valve related complications against the risks of irreversible left ventricular dysfunction as a result of chronic volume overload [18]. Aortic valve replacement carries a 1-3\% operative mortality. The onset of symptom is often used as the indicator of surgical intervention. However, symptoms such as dyspnea and fatigue, which are both insensitive and non-specific, may be absent despite the presence of significant left ventricular dysfunction [18]. In patients with valvular regurgitation, larger ventricular dimensions and pre-existing systolic dysfunction are predictors of perioperative complications, post-operative left ventricular dysfunction and long term mortality $[19,20]$. Various measurements of ventricular function, indicating left ventricular end-systolic size, left ventricular ejection fraction and wall stress, have been used in the follow-up of these patients to guide the timing of surgical intervention [21,22] When mild to moderate left ventricular dysfunction is present, aortic valve replacement is generally indicated even in asymptomatic patients. Nonetheless, in patients with aortic regurgitation and left ventricular dysfunction, the clinical challenge is to distinguish reliably those with from those without favorable operative results [8]. Previous work with radionuclide ventriculography has shown that the ejection fraction during exercise and the change from rest to stress to be abnormal in many patients with aortic regurgitation and these data may be predictive of outcome [23,24] . Echocardiography is a more widely available technique, and exercise echocardiography measurement of ejection fraction and end systolic volume has been shown to predict outcome in patients with mitral regurgitation [25] However, there are limited data to support its use in aortic regurgitation, and in the recent guidelines for the management of patients with valvular heart disease these techniques was given class III indication evidence or general agreement that the procedure is not useful [26]. In this study, we sought to determine whether exercise echocardiography might be used to predict left ventricular dysfunction during post-operative follow-up of patients with severe aortic regurgitation. We hypothesized that impaired left ventricular systolic reserve assessed by low dose dobutamine may be a marker of irreversible left ventricular dysfunction and is used in predicting subsequent changes in left ventricular systolic function and morphology three months following valve replacement. In this study 49 patients with chronic severe aortic regurgitation was divided into two groups according to their resting ejection fraction measured by the biplane modified Simpson method. The cutoff number of ejection fraction used in this study was $<50 \%$. This value was chosen according to the recommendation of the European Society of Cardiology for the indication of surgery in chronic severe aortic regurgitation. Group II included 17 patients with 
ejection fraction $>50 \%$. In this group of patients with preserved left ventricular function the resting end systolic volume, end systolic volume index, end diastolic volume, end diastolic volume index were significantly lower than in Group I patients with resting ejection fraction $<50 \%$. On the other hand the resting stroke volume and ejection fraction were significantly higher than in Group I.

Response of Group II patients to dobutamine infusion: The resting mean ejection fraction of patients in Group II was $62.3 \pm 6 \%$. This value increases non-significantly with $20 \mathrm{u}$ dobutamine to $68.3 \pm 7.5 \%$. The individual patient ejection fraction increased with dobutamine in 13 patients, unchanged in one patient and decreased in three patients. Of the three patients in whom the ejection fraction decreased with dobutamine two had normal three-month post-operative ejection fraction, and one had reduced 3 month ejection fraction. In the 13 patients with dobutamine increased ejection fraction 3 had subnormal ejection fraction three months post-operatively, and 10 had normal three months ejection fraction. The one patient without dobutamine change in ejection fraction the three month post-operative ejection fraction was above normal. By application the McNemar test of agreement we conclude that in patients with resting ejection fraction $>50 \%$ dobutamine infusion did not predict the three month post-operative ejection fraction. Other echocardiographic parameters did not change significantly with dobutamine in this group except the stroke volume which showed significant increase because it included changes in end systolic and end diastolic volumes.

Response of Group II patients to aortic valve replacement: All studied patients in this group showed significant reduction in end systolic volume, end systolic volume index, end diastolic volume, end diastolic volume index and stroke volume in response to aortic valve replacement. The mean ejection fraction did not change in a significant way three months post-operatively, and the resting pre-operative ejection fraction is correlated with the three months post-operative ejection fraction $(r=0.53, p=0.03)$. The resting end systolic volume and end systolic volume index also correlated with the post-operative ejection fraction $(r=0.66, p=0.04)$.

Comparison between the response of Group II patients to aortic valve replacement and peak dobutamine infusion: All echocardiographic measurements showed statistically significant difference between three month post-operative values and peak dobutamine values. So it was concluded that the peak dobutamine echocardiographic values did not predict the three month post-operative values. There was only one study in the literature which used dobutamine stress echocardiography in aortic regurgitation [26]. In this study the investigators gave low dose dobutamine $7.5 \mathrm{ug} / \mathrm{kg} / \mathrm{min}$ to 16 patients undergoing aortic valve replacement. They measured left ventricular end systolic volume index, left ventricular end diastolic volume index and ejection fraction at rest and after 15 minutes of dobutamine infusion. They divided the patients into two groups according to the six month postoperative follow-up. Group I with complete recovery as defined by normalization of left ventricular size and function and the absence of symptoms at the six month follow-up visit. Group II included patients with incomplete recovery of function and left ventricular size. The resting end systolic volume index was significantly lower and the ejection fraction was significantly higher in Group I compared to Group II patients. This difference in ventricular size and function was further accentuated with dobutamine infusion. They concluded that the pre-operative ejection fraction during dobutamine infusion was highly predictive of postoperative ejection fraction and that low dose dobutamine infusion may have a role in predicting the clinical outcome of patients after aortic valve replacement. We analyzed the data of the previous study in a similar way to our study. In the study of Tam et al., [26] 7 patients had ejection fraction $>50 \%$. With dobutamine infusion 5 patients had increase in ejection fraction while 2 patients had no change. In the 5 patients with increase in ejection fraction with dobutamine, the six month postoperative ejection fraction remained within normal. The two patients without increase in ejection fraction with dobutamine had subnormal six month post-operative ejection fraction. The results of the present study are different from that of Tam et al., in the following points:

The protocol for low dose dobutamine is different in the two studies. In the study of Tam et al., infusion dose was $7.5 \mathrm{ug} / \mathrm{kg} / \mathrm{min}$ for $15 \mathrm{mins}$. They selected this dose in order to avoid induction of coronary ischemia by higher doses. In the present study associated coronary artery disease was considered as an exclusion criterion so the infusion dose was started by $5 \mathrm{ug} / \mathrm{kg} / \mathrm{min}$ and increased every 3 minutes till $20 \mathrm{ug} / \mathrm{kg} / \mathrm{min}$.

The follow-up period was 6 months in the study of Tam et al., and 3 months in our study. It was reported in previous study that complete recovery of left ventricular function may take more than 6 months [30] 
In the present study we did not find a correlation between the peak dobutamine values and the postoperative values and low dose dobutamine did not predict the 3 months post-operative ejection fraction in patients with resting ejection fraction $>50 \%$. Gee et al., reported similar results to our study but with radionuclide angiography. They reported an excellent post-operative course in 23 patients despite a decrease in the preoperative exercise ejection fraction in $91 \%$ of their patients. At a mean followup period of 30 months no patient had died of left ventricular dysfunction nor had any patient demonstrated symptoms of congestive heart failure [27]. Bonow et al., reported on long term followup in 80 patients who underwent valve replacement for aortic regurgitation, the majority having a normal ejection fraction at rest and a decrease in ejection fraction with exercise. Survival was excellent. Neither the value of the exercise ejection fraction nor the magnitude of the ejection fraction response to exercise predicted which patients will be at risk of death or left ventricular dysfunction after operation [28]. So we concluded from our study that the peak dobutamine echocardiographic variables did not predict the 3 month post-operative ejection fraction in patients with resting ejection fraction $>50 \%$.

Our explanation is that most of these patients do not use their contractile reserve at rest. Dobutamine infusion augments this contractile reserve much more than augmenting the normal contractility, so the peak dobutamine ejection fraction is increased non-significantly compared to the resting values. We studied 32 patients with resting ejection fraction less than $50 \%$ (Group I). This group was further subdivided into Group IA which included 16 patients with positive contractile response to dobutamine. This group of patients responded to dobutamine by $30 \%$ or more increase in there resting ejection fraction.

The other Group IB included 16 patients without positive contractile response (less than $30 \%$ increase in there resting ejection fraction with dobutamine). There were statistically significant differences in all resting echocardiographic variables between the two groups. Surprisingly, the resting ejection fraction of Group IA was lower than that of Group IB. Group IA responded to aortic valve replacement by significant increase in ejection fraction. Like Group IA, Group IB responded to aortic valve replacement by a similar manner but without significant increase in ejection fraction. Three month after aortic valve replacement ejection fraction increased significantly in Group IA and did not change in Group IB. Group IA responded to dobutamine infusion by a significant increase in ejection fraction. Group IB responded to dobutamine infusion by a non-significant change in ejection fraction. So the most important difference in the response of the two groups to dobutamine infusion is the ejection fraction which increased significantly in Group IA and non-significantly in Group IB. This positive contractile reserve in Group IA was translated into a significant improvement in the 3 month post-operative ejection fraction in the same group. On the other hand, absence of contractile reserve in Group IB was associated with non-significant change in the 3 month postoperative ejection fraction. The findings of these results are similar to that of Wahi et al. [29]. They concluded that in patients undergoing aortic valve replacement, contractile reserve had a better correlation with resting ejection fraction on postoperative follow-up and measurement of contractile reserve may be useful to monitor the early development of myocardial dysfunction. They studied 26 patients undergoing aortic valve replacement. Thirteen patients showed positive contractile reserve (ejection fraction increase by $9 \pm 5 \%$ ) all of whom had an increase in ejection fraction on follow-up from $49 \%$ to $59 \%$. Of 13 patients with negative contractile reserve (ejection fraction decrease by $7 \pm 5 \%$ ) 10 showed the same or worse ejection fraction on the post-operative follow-up. However, our study is different from the study of Wahi et al., in that:

- The studied group in Wahi et al., series had much low left ventricular volumes and better resting ejection fraction.

- Wahi et al., used treadmill exercise testing and we used dobutamine.

- The follow-up period in our study was 3 month and in Wahi et al., study it was 6 month.

- We defined contractile reserve by $>30 \%$ increase in resting ejection fraction with $20 \mathrm{ug} / \mathrm{kg} / \mathrm{min}$ dobutamine infusion. Wahi et al., defined contractile reserve by any augmentation in ejection fraction with exercise.

Wahi et al., reported intra-observer variability for measurement of ejection fraction of $2 \pm 4 \%$ and after exercise of $1 \pm 2 \%$. They also report similar values for inter-observer variability. So, contractile reserve of Wahi et al., should be verified by reproducibility data from reported examinations and not any increase or decrease in ejection fraction considered as $+v e$ or $-\mathrm{ve}$ reserve.

Measurement of ejection fraction: In the present study ejection fraction was measured by 3 methods. 
The first is the M-mode. The second is by single plane method and the third is by biplane Simpson's method. There was statistically significant correlation between the three methods. However, we depend on the biplane Simpson's method in our statistical analysis because it compensates for abnormal post-operative septal motion.

Improvement in dyspnea class: There was significant improvement in dyspnea functional class in Group II patients 3 months after surgery. Wahi et al reported that in patients with normal resting left ventricular function, conventional indices of left ventricular function and size, exercise capacity and clinical characteristics did not predict the latent left ventricular dysfunction on medical follow-up or the improvement in left ventricular function after aortic valve replacement surgery. Contractile reserve and the decrease in end systolic volume with exercise measured by exercise echocardiography were predictive of progressive deterioration of left ventricular function in these patients [29] There was significant improvement in the dyspnea functional class in Group IA compared to Group IB. The better increase in ejection fraction which occurred in Group IA was associated with more improvement in dyspnea class.

Inter-observer variability: Measurements were taken by the first and second observers for measurement of resting ejection fraction and correlation was done. Mean difference between the first and second observers $2.34+1.59$. There was positive correlation where $(r=0.991$ and $p<0.001)$. At peak dobutamine the mean difference between the first and second observers was $0.73+0.3 .1$. There was positive correlation where $(r=0.993$ and $p<0.001)$.

Intra-observer variability: Measurements were taken by the same observer for measurement of resting ejection fraction and correlation was done. Mean difference between the first and second measurement for the same observer was $1.51 \pm 0.7$. There was positive correlation where ( $r=0.996$ and $p<0.001$ ). At peak dobutamine the mean difference was $1.4 \pm 0.53$. There was positive correlation where $(r=0.921$ and $p<0.001)$. Thus, values for interobserver and intra-observer variability were comparable. Wahi et al., reported a mean (SD) intraobserver variability for the recording of resting ejection fraction $(r=0.97)$. After exercise the variability was \% ( $r=0.98)$. Values for inter observer variability were comparable [29].

\section{Conclusion:}

Dobutamine stress echocardiography can be performed safely in patients with chronic severe aortic regurgitation. Dobutamine stress echocardiography is a good predictor of improvement in left ventricular ejection fraction 3 months postoperatively in patients with positive contractile reserve. Dobutamine stress echocardiography is a good predictor of symptomatic improvement in patients with positive contractile reserve.

In patients with negative contractile reserve, there is improvement in ventricular volumes 3 months post-operatively, however, the improvement in ejection fraction and symptoms is minimal. In patients with normal resting ejection fraction, low dose dobutamine stress echocardiography does not predict the 3 month post-operative ejection fraction. Resting ejection fraction and resting end systolic volume correlates better with post-operative ejection fraction in those patients. In patients with normal resting ejection fraction, there is significant symptomatic improvement 3 month after surgery.

\section{References}

1- NISHIMURA R.A., OTTO C.M., BONOW R.O., et al.: AHA/ACC guideline for the management of patients with valvular heart disease: A report of the American College of Cardiology/American Heart Association Task Force on Practice Guidelines. J. Thorac. Cardiovasc. Surg., 148: e132, 2014.

2- VAHANIAN A., ALFIERI O., ANDREOTTI F., et al.: Guidelines on the management of valvular heart disease (Version 2012). The Joint Task Force on the management of Valvular Heart Disease of the European Society of Cardiology (ESC) and the European association for CardioThoracic Surgery (EACTS) Eur. Hear J., 33: 2451-96, 2012.

3- BORER J.S., HOCHREITER C., HERROLD E.M., et al.: Prediction of indications for valve replacement among asymptomatic or minimally symptomatic patients with chronic aortic regurgitation and normal left ventricular performance. Circulation, 97: 525-34, 1998.

4- FORSBERG L.M., NYLANDER E. and TAMAS E.: Exercise echocardiography predicts post-operative left ventricular remodeling in aortic regurgitation. ScandCardiovasc. J. 14; 48: 4-12, 2014.

5- WAHI S., HALUSKA B., PASQUET A., et al.: Exercise echocardiography predicts development of left ventricular dysfunction in medically and surgically treated patients with asymptomatic severe aortic regurgitation. Heart, 84 : 606-14, 2000.

6- BONOW R.O.: Asymptomatic aortic regurgitation: Indications for operation. J. Cardiovasc. Surg., 170, 1994.

7- TANIGUCHI, NAKANO S., MATSUDA H., et al.: Predictors of outcome for aortic valve replacement in patients with aortic regurgitation and left ventricular dysfunction: A change in the measuring sticks. J. Am. Coll. Cardiol., 10: 991, 1989.

8- CARABELLO B.A., USHER B.W., HENDRIX G.H., ASSEY M.E., CRAWFORD F.A. and LEMAN R.B.: 
Predictors of outcome for aortic valve replacement in patients with aortic regurgitation and left ventricular dysfunction: A change in the measuring stick: J. Am. Coll. Cardiol., 10: 991-7, 1987.

9- WISENBOUGH T., BOOTH D., De MARIO A., et al.: Relationship of contractile state to ejection performance in patients with chronic aortic valve disease. Circulation, 73: 47, 1986.

10- SCHULER G., OLSHAUSEN K.V., SCHAURZ F., et al.: Non invasive assessment of myocardial contractility in asymptomatic patients with severe aortic regurgitation and normal left ventricular ejection fraction at rest. Am. J. Cardiol., 50: 54, 1982.

11- HEINLE S.K., TICE F.D. and KISSLO J.: Effect of dobutamine stress echocardiography on mitral regurgitation. J. Am. Coll. Cardiol., 25 (1): 122-7, Jan. 1995.

12- GANONG W.F.: Review of Medical physiology, 13 ed, by Appleton \& Langue, Chapter 17, pp. 232, Energy balance, metabolism and nutrition, 1987.

13- SAHN D.J., DeMARIA A, KISSLO J. and WEYMAN A.: Recommendations regarding quantification in $\mathrm{M}$ mode echocardiography: Results of a survey of echocardiographic measurements. Circulation, 58: 1072, 1978.

14- SCHILLER M.B., et al.: Recommendations for quantitation of the left ventricle by two dimensional echocardiography. J. Am. Soc. Echocardiography, 2: 362, 1989.

15- COOPER D.N., STEWART W.J., SCHIARONE W.A., LOMBARDO H.D., et al.: Evaluation of normal prosthetic valve function by Doppler echocardiography. Am. H. J., 114: 576, 1987.

16- GRAYBURN P.A., SMITH M.D., HARRISON M.R., GURLEY J.C. and DeMARIA A.N.: Pivotal role of aortic valve area calculation by the continuity equation for Doppler assessment of aortic stenosis in patients with combined aortic stenosis and regurgitation. Am. J. Cardiol., 61: 376, 1988.

17- BENGUR A.R., SNIDER A.R., MELIONES J.N. and VERMILION R.P.: Doppler evaluation of aortic valve area in children with aortic stenosis. J. Am. Coll. Cardiol., 18: 1499, 1991.

18- CARABELLO B.A. and CRAWFORD F.A. Jr.: Valvular heart disease. N. Engl. J. Med., 337: 32, 1997.

19-FORMAN R., FIRTH B.G. and BARNARD M.: Prognostic significance of pre-operative left ventricular ejection fraction and valve lesion in patients with aortic valve replacement. Am. J. Cardiol., 45: 1120-5, 1980.
20- ENRIQUEZ-SARANO M., TAJIK A.J., SCHAFF H.V., ORSZULAK T.A., BAILEY K.R. and FRYE R.L.: Echocardiographic prediction of survival after surgical correction of organic mitral regurgitation. Circulation, 90: 830-7, 1994.

21- BOROW K.M.: Surgical outcome in chronic aortic regurgitation: A physiologic framework for assessing preoperative predictors. J. Am. Coll. Cardiol., 10: 1165, 1987.

22- CARABELLO B.A., WILLIAMS H., GASH A.K., et al.: Hemodynamic predictors of outcome in patients undergoing valve replacement. Circulation, 74: 1309-16, 1986.

23- BORER J.S., ROSING D.R., KENT K.M., et al.: Left ventricular function at rest and during exercise after aortic valve replacement in patients with aortic regurgitation. Am. J. Cardiol., 44: 1297, 1979.

24- LINDSAY J., SILVERMAN A., VAN VOORHEES L.B., et al.: Prognostic implications of left ventricular function during exercise in asymptomatic patients with aortic regurgitation. Angology, 38: 386-92, 1987.

25- LEUNG D.Y., GRIFFIN B.P., HALUSKA B., et al.: Left ventricular function after valve repair for chronic mitral regurgitation: Predictive value of pre-operative assessment of contractile reserve by exercise echocardiography. J. Am. Coll. Cardiol., 28: 1198, 1996.

26- TAM J.W., DAVID A., HYUNG H., KENNETH J. and KWAN-LEUNG C.: Low dose dobutamine echocardiography in the assessment of contractile reserve to predict the outcome of valve replacement for chronic aortic regurgitation. Can. J. Cardiol., Vol. 15, No. 1, 1999.

27- GEE D.S., JUNI J.E., SANTINGA J.T. and BUDA A.J.: Prognostic significance of exercise induced left ventricular dysfunction in chronic aortic regurgitation. Am. J. Cardiol., 56: 605-9, 1985.

28- BONOW R.O., PICONE A.L., McINTOSH C.L., et al.: Survival and functional results after aortic valve replacement for aortic regurgitation from 1976 to 1983: Impact of pre-operative left ventricular function. Circulation, 72: 1244-56, 1985.

29- WAHI S., HALUSKA B.A., ARMSTRONG G.P., et al.: Exercise echo predicts outcome in asymptomatic patients with severe aortic regurgitation. Circulation, 98 (suppl 1): $91,1998$.

30- TOUSSAINT C., CRIBIER A., CAZOR J.L., SOYER R. and LETAC B.: Hemodynamic and angiographic evaluation of aortic regurgitation 8 and 27 months after aortic valve replacement. Circulation, 64: 456-63, 1981. 


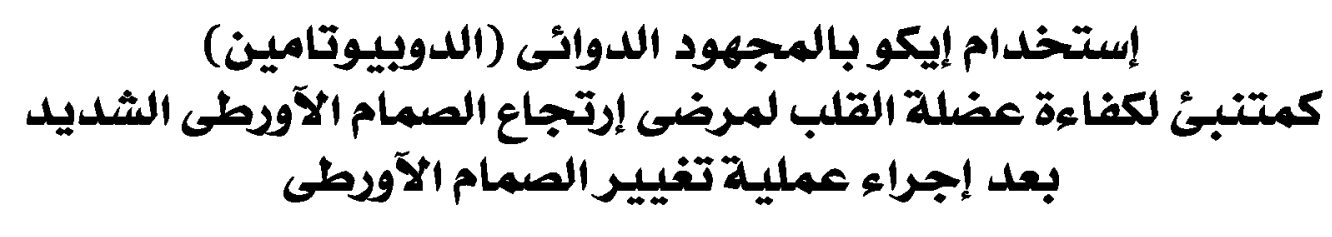

مقدمة: يعتبر إرتجاع الصمام الآورطى من آحد الآمراض الثائعة ويختلف موعد إجراء عملية تغيير الصمام تبعا للحالة العامة للمريض وأعراض المرض وعضلة القلب. الهدف من البحث: يهدف البحث للتبئ بعضلة القلب بعد إجراء عملية تفيير الصمام الآورطى بإستخدام الإيكو الدوائى. المرضى وطرق البحث: 9ع مريض من المرضى الذين يعانون من إرتجاع شديد بالصمام الآورطى وتم تقسيمهم إلى مجموعتين:

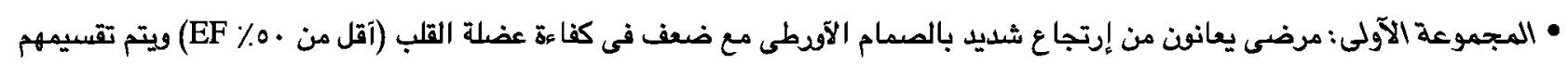

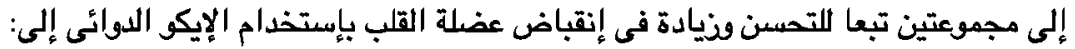

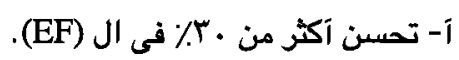

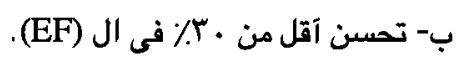

• المجموعة الثانية: مرضى يعانون من إرتجاع شديد بالصمام الآمرطى مع نسبة كفاءة عضلة القلب (آكثر من • EF \%). آهم النتائج: يعتبر إيكو بالمجهود الدوائى متببئ لعضلة القلب بعد عملية تغيير الصمام الآوطى فى المرضى الذين يعانون من إرتجاع

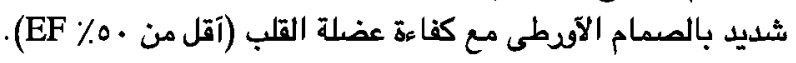

